\title{
A constitucionalidade dos tratados
}

\author{
El tratado de constitucionalidad
}

\section{The constitutionality treaty}

A pesquisa objetiva o debate sobre a constitucionalidade dos tratados internacionais que são incorporados ao direito brasileiro e são, em decorrência, submetidos aos controles hierárquico ordinário e constitucional. O Tema se socorre da incapacidade do homem conseguir, fora da sociedade, resolver alguns dos seus problemas, surgindo o Estado e posteriormente a sociedade internacional. Além disso, o debate sobre o controle de legalidade dos tratados, objeto de estudos exigiu singelos comentários sobre as espécies de controle preventivo e repressivo.
La investigación tiene como objetivo debatir sobre la constitucionalidad delos tratados internacionales que son incorporados a la legislación brasileña y están, en consecuencia, sujetos a los controles jerárquicos ordinários y constitucionales. El Tema se basa principalmente en la incapacidad del hombre para conseguir, fuera de la sociedad, resolver algunos de sus problemas, emergiendo el estado y, posteriormente, la comunidad internacional para intentar resolverlos. Por otra parte, el debate sobre la legalidad del control de los tratados, objeto de estudios, exigió simples comentários sobre los tipos de control preventivo y represivo.
The research aims to debate on the constitutionality of international treaties are incorporated into Brazilian law and are, consequently, subject to the ordinary and constitutional hierarchical controls. The subject and its disposition of man's inability to get, outside of society solve some of their problems, emerging the state and later the international society. Moreover, the debate about legality control treaties, subject of studies required single and comments about the kinds of preventive and repressive control.
Palavras-chave: Direito, Internacional, Constitucional, Legalidade, Tratados

\section{Autor:}

\section{Jorge Pedro Nery}

Prof. Direito Internacional na UNESA; Prof. Banco de Talentos da SSPERJ; Mestrando na UNIPAC; Advogado; Conselheiro da Ordem dos Advogados do Brasil; Ex Diretor da ESA; Autor de artigo publicado na Revista Dissertar $n^{\circ} 8 / 9$.

E-mail: pedronery@terra.com.br

\section{Introdução}

Em decorrência da complexidade que envolve o Direito Constitucional e as disposições normativas de eficácia infraconstitucional, podem ocorrer transgressões dessas normas em relação à Constituição, exigindo se realizem estudos que visem aferir possível inconstitucionalidade. Aferir possível inconstitucionalidade é atividade que se desenvolve por parte de órgão encarregado de elaborar a norma jurídica infraconstitucional, denominado de controle preventivo de constitucionalidade, exercido pelo Legislativo e pelo Executivo. Esse controle também ocorre de forma repressiva, quando não se verifica preventivamente. Nesse caso, o judiciário é chamado a exercer esse controle. Ocorre que não são somente as normas jurídicas elaboradas pelos órgãos estatais, que podem conter vícios que as tornem invalidas. Os tratados internacionais, ao se integrarem ao ordenamento jurídico podem conter vícios que lhes retirem a eficácia interna. $\mathrm{O}$ principal objeto desse artigo é o debate sobre a Constitucionalidade dos tratados internacionais quando incorporados ao ordenamento jurídico brasileiro e possíveis conseqüências em decorrência de sua inconstitucionalidade. A análise sobre constitucionalidade preventiva e repressiva também serão objeto de estudos.

\section{Noções}

Pesquisas buscaram demonstrar o surgimento e organização da sociedade e a Constituição como instrumento de organização do Estado. Assim, a Constituição do Estado dá forma ao projeto político que resulta da vontade dominante dos grupos sociais, política e juridicamente organizados. A Constituição organiza o grupo social que lhe outorga seus poderes, organiza a sociedade enfim, os poderes, os órgãos e os direitos fundamentais. Não é outra a leitura de Giuseppe de Vergottini: "según una orientación más amplia, la Constitución coincide con la estructura organizadora de un grupo social y, por tanto, en el caso del Estado, también con la organización de su comunidad $\mathbf{1}$."

Além daquelas contidas na Constituição, outras normas jurídicas se fazem necessárias à existência do Estado, como aquelas que regulam as relações entre os indivíduos, os indivíduos e as coisas, os indivíduos e o Estado. Tais normas jurídicas são autorizadas pela Constituição. A Constituição é assim, a norma suprema do Estado politicamente organizado. É norma jurídica que exige subordinação por parte das demais normas, não podendo

${ }^{1}$ VERGOTTINI, Giuseppe de; Derecho Constitucional Comparado, traducción Cláudia Herrera, Universidad Nacional Autónoma de México e Segretariato Europeo per le Publicación Scientifiche, México, 2004, p.110 
ser contrariada por dispositivos do direito positivado. Nesse sentido, Jorge Carpizo leciona que "el principio de supremacia constitucional se ha establecido em todas las Constituciones mexicanas" e Kelsen leciona que "a norma que determina a criação de outra norma é a norma superior"3. Não é outra a leitura de Ferrari, segundo o qual, "para uma norma ter validade dentro do sistema necessita ser reproduzida em concordância com os ditames da norma superior, que representa seu fundamento de validade ${ }^{4}$ ". Baracho, por sua vez, leciona que o ordenamento jurídico repousa "sobre uma norma única, que é a fonte comum de todas as outras que pertencem a uma mesma ordem constitucional" " e Bittencourt conclui que a "incompatibilidade ou conflito de uma lei (norma jurídica) ordinária com qualquer preceito da Constituição, dá origem ao estado de inconstitucionalidade, suscetível de reconhecimento pelos tribunais ${ }^{6}$ ". Assim sendo, inconstitucional é a norma jurídica ou o dispositivo com força de lei contrário aos objetivos e a vontade da Constituição. Neste sentido, "se a lei (norma jurídica) ordinária é incompatível com alguma prescrição do Estatuto Político, a inconstitucionalidade é irrecusável ${ }^{7 ’}$.

A jurisdição constitucional é instrumento do Direito Constitucional $^{8}$ e visa o estudo da constitucionalidade das leis por parte de órgão jurisdicional. Binenbojm sustenta que tal instituto surgiu antes do liberalismo do Século XVII ${ }^{9}$. Aristóteles, na obra "A Política" já preceituava que um Estado democrático é governado pelo povo e o governo do povo é o governo da Constituição ${ }^{10}$, devendo a norma jurídica obedecer aos comandos da Constituição ${ }^{11}$. Em tal sentido, no século XVII os ingleses "fizeram com que as Cortes Judiciárias proclamassem a superioridade das normas fundamentais sobre as leis do Parlamento" ${ }^{12}$ ", inspirando os norte-americanos "a iniciarem a codificação do Direito Constitucional e a instituírem moderna forma de governo democrático ${ }^{13}$ ".

A ordem jurídica objetiva o equilíbrio da sociedade $\mathrm{e}^{14}$ sendo que a Jurisdição Constitucional atua em favor desse equilíbrio. Assim leciona Baracho, ao sustentar que a "jurisdição constitucional é compreendida como a parte da administração da justiça que tem por objetivo especificar matéria jurídicoconstitucional de um determinado Estado ${ }^{15}$ ".

2 CARPIZO, Jorge e MADRAZO, Jorge; Derecho Constitucional, Universidad Nacional Autónoma de México, México, 1991, p. 14

${ }^{3}$ KELSEN, Hans; Teoria Geral do Direito e do Estado. Tradução de Luís Carlos Borges. Martins Fontes; São Paulo, 2000, p. 181.

${ }^{4}$ FERRARI, Regina Maria Macedo Nery; Efeitos da Declaração de Inconstitucionalidade, São Paulo, Editora Revista dos Tribunais, 1987, p. 9.

5 BARACHO, José Alfredo de Oliveira; Hermenêutica Constitucional., Revista da Faculdade de Direito de Minas Gerai $n^{\circ} 18$, ano XXV, Belo Horizonte, maio de 1887.

${ }^{6}$ BITTENCOURT, Carlos Alberto Lúcio; O Controle Jurisdicional da Constitucionalidade da Lei, Ed. Brasília: Ministério da Justiça, 1997. p. 60.

${ }^{7}$ BITTENCOURT, op. cit. p. 60

${ }^{8}$ BÉGUIN, Jean-Claude, Le controle de la constitutionnalité des lois Republique Féderale d'Allemagne, Paris, Econômica, 1982, p. 1.

${ }^{9}$ BINENBOJM, Gustavo, A nova jurisdição constitucional brasileira: legitimidade democracia e instrumentos de realização, Rio de Janeiro, ed. Renovar, 2001. p. 17.

10 ARISTÓTELES, Política, ed. Martin Claret, 2001, f. 87.

11 Idem, p. 173.

12 CASTRO JUNIOR, Osvaldo Agripino de, A Democratização do Poder Judiciário, Sergio Porto Fabris Editor, Porto Alegre, 1998 p. 41.

13 Idem, p. 41.

14 ROUSSEAU, Jean-Jacques, Do Contrato Social, Abril Cultural, 1978, p. 56
Para organizar-se como Estado democrático e garantir o respeito aos direitos fundamentais, a Constituição divide a administração do Estado em órgãos, limitando e desconcentrando o poder político de cada um desses órgãos, cabendo ao órgão de controle a constitucionalidade do ordenamento jurídico. Nesse sentido, Gustavo Binenbojm, compreende que compete à jurisdição constitucional "atuar como árbitro do jogo democrático ${ }^{16}$ " e Baracho, em sua obra sobre Jurisdição Constitucional, leciona que é "control constitucional el conjunto de mecanismos de control actuables entre órganos constitucionales y previstos mediata o immediatamente por la constituición. ${ }^{17}$ ". Assim ocorre, visto a supremacia jurídica da Constituição.

\section{Princípio da legalidade}

O principio da legalidade é instituto que exige a sua observância por parte do Estado e seus agentes, nas várias atividades de interesse da sociedade, em relação às quais dispõe do ônus e do direito de agir. Seja administrando, legislando ou julgando. El principio de legalidade es um principio fundamental. Geralmente es reconocido em los ordenamientos supremos de los diferentes Estados ${ }^{\mathbf{1 8}}$.

$\mathrm{O}$ direito constitucional brasileiro prevê as mais variadas espécies de normas jurídicas ${ }^{\mathbf{1 9}}$, e tais espécies exigem do legislador submissão aos preceitos normativos para que validamente venham a integrar o ordenamento jurídico.

Assim, em respeito ao princípio da legalidade, o legislador ordinário deverá respeitar o caráter privativo para deflagrar o processo legislativo, a exemplo, a competência do Presidente da República ${ }^{20}$, sob pena de se incorrer em ilegalidade, gerando a inconstitucionalidade formal da "norma" produzida sem obediência aos requisitos.

O jurista Jean Bodin, autor de "Les Six Livres de la République”, publicado em 1576, obra de fundamental importância para o estudo da soberania e do Estado moderno, fez importante defesa do princípio da legalidade. No Século XVI, quando o rei da França resolveu alienar uma parcela dos domínios da coroa para financiar a guerra contra os protestantes e buscou aprovação por parte dos Estados Gerais. Na oportunidade, Jean Bodin, deputado representante de Vermandois, tomou a palavra na assembléia e defendeu que o rei não é proprietário do domínio da Coroa, mas apenas um usufrutuário. Defendeu que conforme as leis fundamentais, o domínio do reino é inalienável"21.

Respeitar a legalidade significa proceder em conformidade comanormajurídica, em conformidade comanorma constitucional. Para o Estado e seus agentes, o princípio da legalidade se traduz em um não fazer, não exigir faça quando a conduta desejada não encontra amparo normativo. O princípio da legalidade é instituto

\footnotetext{
15 BARACHO, José Alfredo de Oliveira, Processo Constitucional, ed. Forense, Rio de Janeiro, 1984, p. 97

16 BINENBOJM, Gustavo, A nova jurisdição constitucional brasileira: legitimidade democrática e instrumento de realização, ed. Renovar, Rio de Janeiro, 2001, p.10. 17 BARACHO, op., cit., p. 156.

18 Anuário de Derecho Constitucional Latinoamericano - año XV, Montevideo, 2009, pp.97-MONTES, Roberto Islãs. Sobre el princípio de legalidad.Biblioteca Jurídica Virtual del Instituto de Investigaciones Jurídicas de la UNAM.

19 BRASIL, Constituição Federal, artigo 59.

20 Brasil, Constituição Federal, artigo 61, parágrafo $1^{\circ}$.

21 RISCAL, Sandra Aparecida. O Conceito de Soberania em Jean Bodin: Um Estudo do Desenvolvimento das Idéias de Administração Pública, Governo e Estado no Século XVI; Tese de doutorado defendida junto à Universidade Estadual de Campinas em junho de 2001.
} 
que visa combater o poder arbitrário ${ }^{22}$ e tem sua expressão maior na Constituição Federal ${ }^{23}$. "O principio da legalidade é talvez o princípio basilar de toda atividade administrativa. Significa que o

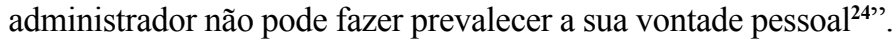
Sua conduta deve se ater ao que determina a norma jurídica.

O Estado e seus agentes estão obrigados pelo princípio da legalidade, devendo pautar suas condutas na Constituição e demais normas jurídicas. Assim, ao se deflagrar o processo legislativo deve o Estado e seus agentes fazê-lo de forma válida e eficaz para não subverter os comandos previstos na Constituição, sob pena desse processo legislativo ter-se por ineficaz, invalido. Não respeitada, por exemplo, a competência privativa do presidente da República no processo Legislativo ${ }^{\mathbf{2 5}}$ para fixar ou modificar o efetivo das forças armadas, a norma jurídica resultante será ilegal, invalida e inconstitucional.

Tal a importância do respeito aos princípios da legalidade que o instituto não se limita ao âmbito da atuação legislativa, ou das práticas adotadas pelos agentes estatais no desenvolvimento das atividades de interesse da sociedade estatal. $\mathrm{O}$ respeito a esse princípio credita os Estado junto aos seus iguais e demais organismos internacionais.

\section{Controle de constitucionalidade}

O controle de Constitucionalidade é modalidade do controle de legalidade e decorre da existência de Constituição rígida. Decorre da supremacia constitucional sobre as demais normas que compõem o ordenamento jurídico do Estado.

O controle é preventivo, quando os órgãos encarregados de elaborar e dar vida normativa a um projeto de lei desenvolvem atividades que visam impedir que o projeto avance contendo vícios de inconstitucionalidade. Esse controle pode ocorrer, ordinariamente, no âmbito do Poder Legislativo e no âmbito do Poder Executivo.

Aos argumentos de que o parlamentar tem o direito de participar de um processo de normalização hígido, sem vícios, o Supremo Tribunal Federal foi chamado a se manifestar a esse respeito, oportunidade em que entendeu que o Judiciário brasileiro não exerce controle material de constitucionalidade de projetos de lei. Entretanto, entendeu ser possível o controle repressivo de constitucionalidade de projeto de lei ou Emenda Constitucional, quando verificada a inconstitucionalidade formal ${ }^{26}$.

A tese que certamente esposa o STF se funda no fato de que a inconstitucionalidade material pode ser corrigida no curso das atividades do parlamento, enquanto que a inconstitucionalidade formal não se convalida. Assim, se órgão do Poder Legislativo propuser projeto de lei e a matéria objeto de tal projeto estiver prevista pela Constituição como sendo de iniciativa de outro poder, haverá ilegalidade, haverá uma inconstitucionalidade formal, inconstitucionalidade que não terá como se corrigir.

\footnotetext{
22 FERREIRA FILHO, Manoel Gonçalves. Curso de Direito Constitucional, $32^{\circ}$ ed., São Paulo, Saraiva, 2006, p. 282 e 283.

23 BRASIL, Constituição Federal, artigo $5^{\circ}$, inciso II.

24 CARVALHO FILHO, José dos Santos; Manual de Direito Administrativo, $8^{\text {a }}$ ed., Editora Lúmen Júris, Rio de Janeiro, 2001, p. 191.

25 Constituição Federal de 1988, artigo 61, parágrafo $1^{\text {o }}$, inciso I. Editora Manole, 2011.

26 BRASIL, Supremo Tribunal Federal. Mandado de Segurança no 32.33, Distrito Federal, Relator: Gilmar Mendes, Relator: Teori Zavascki, julgado em 20/06/2013, Tribunal Pleno, publicado no DJe-033, em 18/04/2014. http://redir. stf.jus.br/paginadorpub/paginador.jsp?docTP $=\mathrm{TP} \&$ docID $=5290006$. Acessado em 29 de agosto de 2015.
}

Nessas circunstâncias, o Supremo poderá sustar o prosseguimento do processo legislativo.

No julgado citado, entendeu-se que o Remédio Constitucional adequado seria o Mandado de Segurança, proposto, única e exclusivamente por parlamentar. Acredita-se que talvez se possa alargar essa capacidade postulatória para propor o MS aos Poderes que disponham de interesse de agir, como o Presidente da República, na inobservância das prerrogativas previstas no artigo $61,1^{\circ}$ da Constituição Federal.

\section{Controle preventivo de constitucionalidade}

$\mathrm{O}$ controle preventivo de constitucionalidade busca impedir que Projetos de Lei ou de Emenda Constitucional sejam aprovados pelo Congresso Nacional com vícios de ilegalidade ou de inconstitucionalidade. Seja inconstitucionalidade material, seja inconstitucionalidade formal. É uma espécie de competência que não é exclusiva do Congresso Nacional e o Presidente da República, quando se tratar de lei federal, também dispõe do poder de exercer o controle preventivo de constitucionalidade.

As Casas do Congresso Nacional dispõem de várias Comissões. Dentre estas, na Câmara dos Deputados, a Comissão de Constituição, Justiça e Cidadania, com atribuição para, dentre outras, deliberar sobre questões de constitucionalidade de projeto de lei ou projeto de Emenda Constitucional, conforme artigo 32, inciso III do seu Regimento Interno. No Senado Federal essa Competência está prevista nos artigos 71 e 72, inciso III c/c artigo 101, inciso I e parágrafo $1^{\circ}$ do seu Regimento Interno.

\section{Controle de constitucionalidade posterior}

$\mathrm{O}$ controle de constitucionalidade posterior ou repressivo ocorre no âmbito do Poder Judiciário e visa seja declarada a inconstitucionalidade de Lei ou ato normativo que afronta a Constituição. Nesse caso a Lei ou ato normativo é considerado nulo pela existência de vícios que lhes tiram as condições mínimas necessárias para ser eficaz.

\section{Controle incidental ou difuso}

O controle incidental de constitucionalidade, também chamado de controle difuso ou judicial review, tem seus fundamentos teóricos nas formulações de Alexander Hamilton, James Madison e John Jay, e veio a público por intermédio da revista "Os Federalistas", publicada em 1787/178827 e sustentado pelo presidente da Corte Suprema dos Estados Unidos no caso Marbury versus Madison, oportunidade em que firmou-se a teoria de que na Constituição estão as normas superior às normas jurídicas que decorrem das leis e demais dispositivos normativos, e os juizes são obrigados a reconhecer essa superioridade quando houver oposição entre a norma ordinária e a norma constitucional ${ }^{28}$.

\section{Controle jurisdicional de constitucionalidade de forma concentrada}

Com o final da Primeira Guerra Mundial em 1919, por força do Tratado de Versalhes, nasceu a República da Áustria, e como todo Estado, precisava de uma Constituição. Hans Kelsen, que já havia sido professor do curso de Direito na Faculdade de Viena, foi chamado para colaborar na elaboração da Constituição da Áustria de 1920. Sob sua influência a Carta política da Áustria inovou ao introduzir no Direito Constitucional a teoria do controle

\footnotetext{
27 “Os Artigos Federalistas". Editora Nova Fronteira, 1987 e traduzida por BORGES, Maria Luiza.

28 Op.cit. p. 153.
} 
concentrado de constitucionalidades das leis e atos normativos; fazendo surgir o Tribunal Constitucional, Corte competente para exercer o controle de constitucionalidade de forma direta ${ }^{29}$.

\section{Controle repressivo de constitucionalidade por parte do Chefe do Poder Executivo}

Todo aquele que se dispõe a exercer uma função no interesse da sociedade brasileira, seja a função de caráter político ou vinculado, promete, inevitavelmente, respeitar e se submeter à vontade normativa da Constituição. Ainda que a promessa não seja expressa, formal, ela ocorre. Seja o varredor de rua, o juiz, o deputado ou o Presidente da República. O Presidente da República, Chefe de um dos Poderes da República não pode deixar de cumprir com suas obrigações aos argumentos de carecer de resolução de qualquer outro Poder que se encontre inerte, ainda que provocado.

É possível que uma "norma jurídica" venha a dobrar o valor da folha de pagamento dos militares, por exemplo, sem que tenha tido a participação do Presidente eleito na elaboração, aprovação, sanção e publicação da "lei"? Acrescente-se ainda que, caso o Presidente efetive tais pagamentos deixará de cumprir com outras obrigações previstas em orçamento.

O STF, no Recurso ao MS 7.999/1959, Relator o Ministro Gonçalves de Oliveira, reconheceu a constitucionalidade da Lei $\mathrm{n}^{\circ} 4.468$ de 11 de abril de 1959. Lei editada pelo Poder Executivo do Ceará, declarando a inconstitucionalidade da Lei $n^{\circ}$. 4.222, conforme artigos 123 e 124 da Constituição do Estado do Ceará. Dispositivos que não permitiam encargos ao Estado sem a devida captação de recursos para custear as despesas.

No julgamento do Mandado de Segurança 7.243, o Ministro Luiz Galotti adotou tese do professor Cáio Tácito, defendendo que os poderes legislativos e executivos podem anular seus próprios atos, quando os consideram inconstitucionais.

A lei anulada, em espaço de apenas 56 dias, transformou e criou 3.784 novos cargos, elevou os vencimentos dos coletores de rendas do interior, de $\mathrm{Cr} \$ 1.500,00$ para $\mathrm{Cr} \$ 26.000,00$, valor esse, equivalente aos vencimentos de Desembargadores e de Secretário de Estado. Assistentes, com vencimentos de Cr\$3.650,00 foram transformados em Assessores Técnicos, com vencimentos de $\mathrm{Cr} \$ 26.000,00$. Professor auxiliar saltou dos Cr\$ 750,00 para Cr\$ 10.000,00 etc.

Os citados artigos daquela Constituição Estadual, além de vedar a criação de novos cargos, também proibiam o dispêndio de mais de $50 \%$ das rendas estaduais com o funcionalismo público, o que elevava a despesa do Estado para algo em torno de $90 \%$ da arrecadação do Estado. Com a declaração de inconstitucionalidade daquela lei, o executivo, além de corrigir o abuso de poder praticado pela legislatura anterior, não exerceu somente a função legislativa, mas, também, e acima de tudo, cumpriu com o compromisso de defender a Constituição. Conforme entendimento de Cândido Mota filho: "o zelo pela integridade do regime não é, por certo, privilégio do Poder Judiciário, uma vez que todos os Poderes da República são guardas da Constituição ${ }^{30}$ ". A tese de que o Poder Executivo pode anular os seus atos ilegais ou inconstitucionais, encontra amparo na jurisprudência dos Tribunais ${ }^{31}$.

Dessa forma, o acórdão confirmou a competência do Executivo para desfazer leis contrárias à ordem pública. De outra parte, não excluiu a competência do Judiciário no sentido de analisar, em última instância, os fundamentos da anulação.

\footnotetext{
29 Kelsen, Hans. Jurisdição Constitucional; $1^{\text {a }}$ edição, 2003, Ed. Martins Fonte, São Paulo.

30 Revista Trimestral de jurisprudência, volume 3, página 760.

31 Idem.
}

A competência para exame de constitucionalidade não é exclusiva do Poder Judiciário e o Supremo Tribunal Federal já havia assim se posicionado no Mandado de Segurança $2.497^{32}$, oportunidade em que o Ministro Nelson Hungria, seguido pelo pleno do Tribunal, reconheceu a constitucionalidade do decreto do prefeito Jânio Quadros, que declarou nulo e sem nenhum efeito, em face da sua inconstitucionalidade, leis estaduais que beneficiavam funcionários ${ }^{33}$. Em outro acórdão, o Tribunal Pleno, com base no relato do Ministro Cândido Mota, reconheceu a legalidade da declaração de inconstitucionalidade do Governo da Paraíba em relação à Lei estadual $1.551^{34}$.

Não é outra a tese defendida por Clenício da Silva Duarte ${ }^{35}$, que sustenta ser lícito ao Poder Executivo negar cumprimento a lei que julgue inconstitucional, não ficando obrigado ao pronunciamento prévio do Judiciário. Seu parecer fundamentou o Mandado de Segurança $n^{\circ} 15.886$ e o Supremo Tribunal Federal em Acórdão publicado em 27 de maio de 1966 no Diário da União, seguiu posicionamento favorável a essa tese, completando que o ato do Poder Executivo foi praticado antes da vigência da Emenda Constitucional $n^{\circ} 16$ de 1965, emenda que deu nova redação ao artigo 101 daquela Constituição e passou a prever a representação contra inconstitucionalidade de lei ou ato de natureza normativa, federal ou estadual.

A norma que conflita com a Constituição não pode gerar efeitos. Pontes de Miranda dizia que "o nulo é negação de validade" ${ }^{36}$ ". Kelsen, por sua vez, defendeu que "uma norma

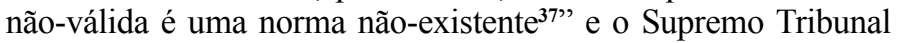
Federal, no julgamento do Mandado de Segurança $n^{\circ} 15.886 / \mathrm{DF}$ entendeu que "a 'lei' inconstitucional é absolutamente nula ${ }^{38}$ ".

$\mathrm{O}$ poder que tem o chefe do executivo, no sentido de se recusar a cumprir norma inconstitucional não é um poder exclusivo do executivo, considerando que ninguém é obrigado a fazer ou deixar de fazer alguma coisa senão em virtude de lei $\mathrm{i}^{39} \mathbf{4 0}$.

Ainda que alguns prestigiados escritores tenham encerrado o debate sobre a possibilidade do executivo se recusar a cumprir norma jurídica inconstitucional, o que faz Zeno Veloso ${ }^{41}$ e Gilmar Mendes $^{42}$, a questão, quer parecer, ainda estar longe de ser esgotada. Assim é o que parece pensar, Carrilo Flores, quando sustenta que o problema para se saber se a autoridade administrativa dispõe da faculdade para "no aplicar una ley en sentido formal y material

\footnotetext{
32 Revista de Direito Administrativo, v. 42, pág. 230

33 Idem

34 Mandado de Segurança 4.211, in Revista Trimestral de Jurisprudência, vol. 2, p. 386

35 DUARTE, Clenício da Silva, Inconstitucionalidade de lei, Ed. Revista de Direito Público - RDP no 2, fls. 150 a 155

36 MIRANDA, Pontes de, Tratado de Direito Privado, Tomo IV, $4^{\mathrm{a}}$ ed., 1974.

37 KELSEN, Hans, Teoria Geral do Direito e do Estado, tradução de Luiz Carlos Borges, Ed. Martins Fontes, São Paulo, 2000, fls. 224.

38 R.T.J. 41, fls, 679

${ }^{39}$ Artigo, $5^{\circ}$, inciso II da Constituição Federal da República Federativa do Brasil.

40 (...) Na orientação que se impõe em Estado de Direito, a lei inconstitucional não é lei, não obriga sequer o particular, e, muito menos, aos órgãos executivos da administração pública. Como já se tem decidido, a aparência de legalidade de que se reveste a lei ordinária, quando afronta ostensivamente quer na elaboração, quer na essência, a Carta Magna, despe-se de sua própria força e autoridade. Não somente pode como deve o Poder Executivo negar-lhe cumprimento, para dar cumprimento à Lei Maior, na defesa de suas prerrogativas e dos princípios institucionais do Estado de Direitos. RT, 374, fls 155.

41 VELOSO, Zeno; Controle Jurisdicional de Constitucionalidade. Editora Del Rei. Belo Horizonte. 2003 P. 311.
} 
porque la estime contraria a un precepto constitucional, es uno de los más importantes temas que se hayan suscitado ${ }^{43 "}$ no mundo jurídico. Do mesmo modo, Também visando reascender o debate sobre o tema proposto Ana Cláudia sustenta que a rejeição de leis inconstitucionais pela autoridade administrativa é legítimo ${ }^{44}$.

\section{Constitucionalidade dos tratados internacionais}

A sociedade surge decorrente de uma vontade racional ou de um processo de evolução natural, resultante da impossibilidade do homem conseguir, sozinho, resolver alguns dos grandes problemas decorrentes do convívio com seus iguais. Naturalmente, determinados indivíduos foram ocupando posição de liderança no grupo, ao passo que outros foram aceitando essa liderança, chegando ao que é hoje a sociedade, o Estado. Em sociedade as pessoas se relacionam em conformidade com a ordem jurídica estabelecida. Por essa ordem, as pessoas são dotadas de direitos e deveres.

Ocorre que os Estados, sozinhos, de forma individualizada, não conseguiram atender plenamente aos seus propósitos, em face da existência de poderosas instituições mais ricas que os Estados $^{45}$, fazendo-se necessária a união entre eles, para em conjunto atenderem aos interesses da sociedade.

Estados da África, como Angola, tem sido palco de conflitos armados, angolanos matando angolanos com armas e munição que não foram fabricadas por eles, mas compradas de mercadores da morte e pagas com os denominados "diamantes de sangue". Organizações Internacionais africanas foram criadas, visando a unificação da luta desarmada em favor da vida nesse continente, mas o poder das empresas multinacionais que atuam nessa e em outras regiões do planeta é demais para um povo que, ainda, em boa parte, vive uma realidade tribal. Sem educação e sem preparo para viverem em um mundo onde as pessoas são portadores de direitos inerentes a pessoa humana.

Mesmo no Brasil, país que desponta no cenário internacional como portador de riquezas que desfrutam seu povo, país economicamente bem posicionado no cenário mundial, com cidades modernas e infraestrutura de transporte público, medicina pública, educação e cultura prestada e incentivada com recursos público, é visível o outro lado dessa realidade sob as marquises dos prédios e nas padiolas dos hospitais do Estado. Não são poucos os desabrigados que se socorrem dessas coberturas nos grandes centros populacionais. $\mathrm{O}$ índio, nativo originário dessa terra, esta longe dos holofotes da mídia.

Assim, enquanto a sociedade, por intermédio do Direito, regula as relações entre as pessoas, outras relações que não se circunscrevem ao âmbito da sociedade estatal carecem de regulamentação, para que também entre elas, sobreviva o justo.

As relações de vizinhança estão reguladas em Códigos de vizinhança. Normas jurídicas de eficácia municipal, estadual e federal impõem aos vizinhos determinadas condutas. No âmbito patrimonial, familiar, etc., leis exigem um fazer ou um não fazer.

\footnotetext{
42 MENDES, Gilmar Ferreira; Jurisdição Constitucional. O Controle Abstrato de Normas no Brasil e na Alemanha. Editora Saraiva. 1999. p. 134.

43 FLORES, Antonio Carrillo; Estúdios de Derecho Administrativo y Constitucional. Instituto de Investigaciones Jurídicas, México, 1987. p. 87.

44 GOMES, Ana Cláudia Nascimento; O Poder de Rejeição de Leis Inconstitucionais pela Autoridade Administrativa no Direito Português e no Direito Brasileiro. Sergio Antonio Fabris Editor. Porto Alegre, 2002. p. 355

45 "as pessoas estão mais ricas que os Estados. As 15 pessoas mais ricas ultrapassam o PIB da África Subsaárica...” MELLO, Celso D. de Albuquerque. Curso de Direito Internacional Público. $1^{\mathrm{o}}$ vol., $14^{\mathrm{a}}$ ed. , ed. Renovar, Rio de Janeiro, 2002, pág. 61 .
}

Essas leis são criadas pela sociedade, por intermédio do poder competente para legislar, e são produzidas e impostas de forma vertical, aplicando-se a todos, indistintamente. Assim, todo empregador esta obrigado pelas leis que regulam as relações de emprego.

E os Estados soberanos, como procedem nas suas relações, uns com os outros? O Brasil não está submetido ao ordenamento jurídico norte americano; a Itália não esta submetida ao ordenamento jurídico brasileiro. Então, o que faz com que um Estado soberano não invada o território de um outro Estado também soberano, mas militarmente inferior?

Assim como a conduta entre os indivíduos, no âmbito interno dos Estados são reguladas por normas estatais, normas verticais hierarquizantes, nas relações entre os Estados soberanos há que existir normas jurídicas. Normas jurídicas que não podem ser criadas de forma individualizada por um dos interessados e imposta aos demais. Também não podem ser criadas por poder legislativo internacional, já que não existe poder legislativo para a sociedade internacional; as normas jurídicas internacionais são horizontalizadas, são criadas pelas mesmas pessoas que em relação a elas se obrigarão. $O$ tratado considerado mais importante para a humanidade é a Carta de São Francisco, tratado esse que criou a Organização das Nações Unidas - ONU. É considerado o mais importante tendo em vista que seus objetivos se direcionam em favor da paz entre todos os povos. Esse tratado foi criado, aprovado e ratificado por 51 estados. Assim, esses 51 Estados se comprometeram por cumprir e fazer cumprir os termos do tratado. Hoje, mais de 190 Estados são signatários da ONU. Quase todos os Estados do mundo. Na América, 35 Estados soberanos são integrantes da Organização dos Estados Americanos - OEA. Organização que objetiva a paz na América.

É essa capacidade que dispõem os Estados para firmar compromissos com outros Estados, criando, em conjunto, normas em relação às quais se comprometem que caracteriza a sociedade internacional. É por intermédio dessa capacidade de pactuar entre si, que os Estados criaram outras pessoas internacionais. Assim como a pessoa física criou a pessoa jurídica, no âmbito internacional os Estados criaram as Organizações Internacionais.

Já foi dito que a pessoa humana é o objeto do direito. O Estado e a sociedade internacional objetivam a dignidade da pessoa humana. Dessa forma, a pessoa humana é também pessoa de direitos e deveres na ordem jurídica internacional. Por força do Pacto de San José da Costa Rica o indivíduo pode demandar junto a Corte Interamericana de Direitos Humanos em face de um Estado, em relação a direito fundamental, provandose com isso, se tratar de pessoa de direitos internacionais. De outra parte, os lideres nazistas foram julgados e alguns condenados por uma Corte internacional que foi denominado de "o julgamento de Nuremberg". Além disso, outros lideres estadistas foram julgados e condenados pelo Tribunal Penal Internacional, provando-se, por fim, que a pessoa humana e sujeito de deveres internacionais.

Portanto, assim como existe uma sociedade interna, sociedade estatal verticalizada, composta pelas pessoas dos Estados, existe ainda uma sociedade internacional, composta pelas pessoas internacionais. Ou seja: os Estados, as Organizações Internacionais e a pessoa humana. São essas, as pessoas de direitos e deveres na ordem jurídica internacional.

Observe-se, entretanto, que tais direitos e deveres decorrem da prévia e expressa manifestação do Estado no sentido de se obrigar em relação a esse ou aquele tratado internacional. Sem essa manifestação obrigacional, sem esse 
compromisso, não há qualquer dever do Estado no sentido de cumprir o que está previsto no tratado. As pessoas internacionais não são obrigadas a se comprometerem em relação a esse ou aquele pacto internacional, entretanto, comprometidas, devem cumprir o pacto de boa-fé.

Os tratados internacionais são, em suma, as normas jurídicas internacionais e resultantes da manifestação das pessoas Internacionais que aceitam se submeter à vontade da norma por eles criada ${ }^{46}$.

Esse compromisso, denominado ratificação ou adesão, que manifestam as pessoas internacionais no âmbito do Direito Internacional, é regulado por normas internacional. Nesse sentido é o artigo $7^{\circ}$ parágrafo $2^{\circ}$ da Convenção de Viena sobre Direito dos Tratados de 1.969. Conforme exigência do artigo 84, inciso VIII da Constituição Federal, é o presidente da República a autoridade competente para manifestar o compromisso do Brasil. Não é assim, competência da autoridade do Poder Legislativo, ou da autoridade do Poder Judiciário. Dessa sorte, o Poder Judiciário do Brasil não tem ingerência internacional. O Poder Judiciário não dispõe da autoridade para intervir no compromisso firmado pelo Brasil. Isso, inclusive a luz do que preceitua o artigo 26 da Convenção de Viena sobre Direito dos Tratados de 1969 - CVDT/69.

Dessa forma, o debate sobre constitucionalidade ou inconstitucionalidade de um tratado internacional no âmbito do Poder Judiciário se limita ao decreto presidencial de incorporação do tratado no ordenamento jurídico do Brasil. Em relação a este sim, poderá o Judiciário declarar a inconstitucionalidade. Assim, é a norma jurídica que da força normativa interna ao tratado internacional, que poderá perder sua eficácia com base em resolução jurisdicional, e não o tratado internacional, o tratado continuará vivo e eficaz, impondo direitos e deveres em relação a quem assumiu tal compromisso.

Quando há interesse do Brasil em relação a um tratado internacional, é o Presidente da República competente para manifestar o compromisso do Brasil de cumprir e fazer cumprir os termos do tratado internacional ${ }^{47}$. Ocorre que antes de ratificar o tratado, o Presidente da República precisa de autorização do Congresso Nacional ${ }^{48}$ para fazê-lo. Essa é uma característica que faz racionalmente necessária, tendo em vista que evita venha o Presidente ser coagido a ratificar acordos em relação ao qual não há interesse para o povo brasileiro, além de impedir ainda, venha se valer desse poder em proveito próprio.

É nesse ponto que as questões relativas ao controle de constitucionalidade dos tratados se submetem a tratamento diferenciado.

Quando ocorre o conflito aparente de normas, instituto aplicado em relação às normas de mesma hierarquia, o aparente conflito se resolve pelo princípio da temporariedade ou da especialidade. Assim, a norma mais recente revoga a norma menos recente ou, a norma especial revoga a norma geral. Assim, parece ser essa a solução prática para tais problemas. Ocorre, entretanto, que uma norma brasileira não tem o poder de revogar um tratado internacional. Por intermédio do tratado o Estado

\footnotetext{
46 Exemplifica a Convenção de Viena Sobre Direito dos Tratados de 1969, internalizada no Brasil, pelo Decreto 7.030 de 14/12/2009. In Coletânea de Direito Internacional, organizada por MAZZUOLI, Valério de Oliveira, Ed. Revista dos Tribunais, $9^{\mathrm{a}}$ edição, São Paulo, 2010, p. 469.

47 BRASIL, Constituição Federal, artigo 84, inciso VIII.

48 BRASIL, Constituição Federal, artigo 49, inciso I.

da Convenção.
}

assume compromissos com outros Estados e não pode, fundado em argumentos unilaterais romper o acordo. Nesse sentido o artigo $26^{49}$ da Convenção de Viena sobre Direito dos Tratados de 1969. Nem a superveniente declaração de inconstitucionalidade do tratado pode ser utilizada para justificar o inadimplemento de um tratado internacional, conforme sustenta o artigo $27^{\mathbf{5 0}} \mathrm{da}$ Convenção citada.

Se compararmos, o que é plenamente adequado, considerando que tratado internacional e contrato são espécies de pacto, aquele que deixa de cumprir os termos de um contrato de forma unilateral poderá sofrer as conseqüências pelo inadimplemento. Imaginem-se as conseqüências que poderão sofrer um indivíduo que deixa de efetuar o pagamento referente a um contrato locatício; aquele que deixa de efetivar o pagamento do cartão de crédito. Trata-se de uma relação pactual que envolve interesses diminutos, se comparados com os compromissos firmados por Estados em relação a um tratado. Na relação locatícia poderá o fiador ser onerado, sofrendo as conseqüências da generosidade. No caso do cartão de crédito poderá sofrer as conseqüências da negativação junto comércio e perder a credibilidade, além de poder vir a ser processado judicialmente e acabar pagando muito mais como conseqüência do seu descontrole.

Se, no âmbito das relações entre pessoas de direito interno, as conseqüências pelo descumprimento de uma obrigação pode causar sofrimento e se tornar um desastre na vida do indivíduo, imaginem-se as conseqüências sobre um Estado que deixar de cumprir com um compromisso internacional. O artigo 41, 42 e 43, dentro outros, da Carta de São Francisco de 1945, acordo que criou a Organização das Nações Unidas, ratificada e promulgada pelo Brasil em 12 de setembro de 1945, prevê, inclusive, se necessário for, a utilização de força bélica para fins de manutenção da paz ameaçada por alguma força militar.

Imaginemos que por uma razão qualquer, ainda que absurda, o Brasil tenha participado da celebração de um acordo internacional que prevê a fiscalização por um organismo internacional para a pesca da sardinha no mar territorial desses Estados. O acordo prevê que todas as embarcações, inclusive do Brasil, para de sardinha devem realizar registros específico nesse organismo, com sede em São Paulo. Após devidamente ratificado o tratado pelo Brasil, foi ele promulgado e publicado no órgão oficial. Com isso, todo pescador de sardinha deve cumprir o que estabelece a lei que promulgou o tratado. Ocorre que um dos que dispõe de capacidade postulatória resolve promover demanda judicial questionando a constitucionalidade desse tratado e ingressa junto ao Supremo Tribunal Federal com esse objetivo. Declarada a inconstitucionalidade, estarão os pescadores desobrigados de fazer o registro previsto no tratado? E o Brasil, estará desobrigado em relação ao acordo internacional?

Aquestão é até simples. As normas jurídicas aprovadas pelo Congresso Nacional, envolvem direitos e deveres para as pessoas de direito e deveres de âmbito interno. O Manoel, o Joaquim, o Paulo, a Padaria Flores, o Mercado Estrela, etc. p.e. Declarada a inconstitucionalidade de determinada norma, essas serão as pessoas que por força da reconhecida inconstitucionalidade deixarão de ser obrigadas a cumprir o que determinara a norma. Assim, as conseqüências da declaração de inconstitucionalidade de norma jurídica se impõe sobre as pessoas de direito interno. Assim, perfeitamente assim não ocorre quando houver declaração

\footnotetext{
49 "Todo tratado em vigor obriga as partes e deve ser cumprido por elas de boa fé".

50 "Uma parte não pode invocar as disposições de seu direito interno para justificar o inadimplemento de um tratado". Salvas as ressalvas do artigo 46
} 
de inconstitucionalidade de tratado internacional internalizado. É que no tratado, as pessoas obrigadas a fazer ou deixar de fazer alguma coisa são pessoas internacionais. Se o Brasil se compromete em relação a um tratado, somente poderá deixar de cumprir se lhe for autorizado pelos demais pactuantes, e não por força de decisão de órgão interno do Estado.

\section{Conclusão}

$\mathrm{O}$ artigo que se apresenta objetiva ser, instrumento de orientação dos estudos sobre o Direito Internacional em relação a possíveis conseqüências que podem decorrer do descumprimento de um tratado internacional por parte de um Estado. Ainda que referido descumprimento decorra de declarada de inconstitucionalidade superveniente ou de conflito aparente de norma. Isso, considerando que no âmbito da sociedade internacional não se admite unilateralidades, salvas as exceções que foram consideradas válidas pela Corte Internacional de Justiça. Tema esse que não foi objeto da nossa atenção. Não é possível, salvas exceções, que uma pessoa internacional, unilateralmente deixe de cumprir um compromisso internacional já firmado. Ainda que se argua conflito com norma jurídica interna.

Para chegarmos a esse ponto que é o objeto da pesquisa, ilustramos o trabalho com estudos sobre o que, possivelmente, teria levou os Estados a se organizarem em sociedade, fazendo nascer a sociedade internacional. Já que nos referimos a constitucionalidade, o controle preventivo e repressivo também ilustrou a pesquisa.

\section{Bibliografia}

AMARAL SANTOS, Moacyr, Primeiras linhas do direito processual civil, São Paulo, $1^{\circ}$ vol., $14^{\mathrm{a}}$ ed., Ed. Saraiva, 1990.

ARAGÓN, Miguel. Constitución, democracia y control. Universidad Nacional Autônoma de México, México, 2002.

BARACHO, José Alfredo de Oliveira, Hermenêutica e Jurisdição Constitucional, ed. Del Rey

BARBI, Celso Agrícola, Comentários ao Código de Processo Civil, vol. I, Rio de Janeiro, Ed. Forense, 1998.

BELAUNDE, Domingo Garcia. Derecho Procesal Constitucional. Marsol, Perú editores s/a, 1998.

El Constitucionalismo peruano en la presente centuria, Universidad Externato de Colombia, Bogotá, Colombia, 1990.

BINENBOJM, Gustavo, A Nova Jurisdição Constitucional Brasileira: legitimidade democrática, ed. Renovar, Rio de Janeiro, 2001.

BITTENCOURT, Carlos Alberto Lúcio. O Controle Jurisdicional da Constitucionalidade das Leis. Atualizado por José Aguiar Dias. $2^{\mathrm{a}}$ edição. Brasília: Ministério da Justiça. 1997.

CAPPELLETTI, Mauro, O controle judicial de constitucionalidade das leis no direito comparado. $2^{\mathrm{a}}$ edição. Reimpresso. Tradução de Aroldo Plínio Gonçalves. Sergio Antônio Fabris Editor. Porto Alegre. 1999.

CARPIZO, Jorge y MADRAZO, Jorge. Derecho Constitucional. Universidad Nacional Autónoma de México, 1991.

CASTRO JÚNIOR, Osvaldo Agripino de. A democratização do Poder Judiciário. Sergio Porto Editor. Porto Alegre. 1998.

CLÈVE, Clèmerson Merlin. A fiscalização abstrata da constitucionalidade no direito brasileiro. $2^{\mathrm{a}}$ edição. $2^{\mathrm{a}}$ tiragem. São Paulo. Editora Revista dos Tribunais, 2000.

FERRARI, Regina Maria Macedo Nery. Efeitos da declaração de inconstitucionalidade. São Paulo. Editora Revista dos Tribunais. 1987.

FIX-ZAMUDIO, Héctor. Veinticinco años de evolución de la Justicia Constitucional -1940 - 1965, UNAM, 1968.

FLORES, Antonio Carrillo. Estudios de Derecho Administrativo y
Constitucional. Universidad Nacional Autónoma de México, 1987.

GIMÉNEZ, Gilberto. Poder, estado y discurso - Perspectivas sociológicas y semiológicas del discurso político-jurídico. Universidad Nacional Autónoma de México, 1981.

HARO, Ricardo. Constitución poder y control. Universidad Nacional Autónoma de México, 2002.

GUASTINI, Ricardo. Estudios de teoría constitucional. Universidad Nacional Autónoma de México, 2001.

IHERING, Rudolf Von, A Luta Pelo Direito, Tradução Pietro Nassetti, Ed. Martin Claret, 2001.

LANDA, César. Tribunal Constitucional y Estado Democrático. Pontifícia Universidad Católica del Perú, 1999.

LASSALE, Fernando. ¿Que es una Constitución? Editorial Cenit S/a, 1931.

MADRID, Miguel de la. Constitución Estado de derecho y democracia. Instituto de Investigaciones Jurídicas, México, 2004.

MELLO, Celso Albuquerque de. Teoria dos direitos fundamentais. Rio de Janeiro. Renovar. 1999.

MONTEIRO, João, Teoria do Processo Civil, $6^{\text {a }}$ ed. Tomo I, Ed. Borsai, Rio de Janeiro, 1956.

NERY JR, Nelson, Princípios do Processo Civil na Constituição Federal, $2^{\mathrm{a}}$ ed. São Paulo: Revista dos Tribunais, 1995

ROUSSEAU, Jean Jacques. Do contrato social, Os Pensadores, Abril Cultural, 1978.

VALADÉS, Diego. Constitución y Política, segunda edición. Universidad Autónoma de México, México, 1994.

VANOSSI, Jorge Reinaldo A. Estudios de teoría constitucional. Universidad Nacional Autónoma de México.

VERGOTTINI, Giuseppe de. Derecho Constitucional comparado. Segretariato Europeo per le pubblicazioni Scientifiche e Universidad Nacional Autónoma de México, 2004.

VIADEL, Antonio Colomer. Estudios Constitucionales. Universidad Nacional Autónoma de México, 1994. 